\title{
The formation conditions of birch tar in oxygen-depleted environments
}

\author{
Tabea J. Koch ${ }^{1}$ (D) Patrick Schmidt ${ }^{1,2}$ (D) \\ Received: 5 March 2021 / Accepted: 20 April 2021 / Published online: 12 May 2021 \\ (C) The Author(s) 2021
}

\begin{abstract}
Birch tar is the oldest manmade adhesive dating back to the European Middle Palaeolithic. Its study is of importance for understanding the cognitive capacities and technical skills of Neanderthals and the aceramic production systems employed in the European Palaeolithic and Mesolithic. Several methods may have been used to make birch tar, the most common proposition being dry distillation in oxygen-depleted atmospheres. One of the major impediments for our understanding of the conditions employed to make Neanderthal birch tar, and ultimately the technique used, is that it remains unknown at which temperatures exactly birch tar forms. The relationship between heating duration and tar formation is also unknown. To address these questions, we conduct a laboratory heating experiment, using sealed glass tubes and an electric furnace. We found that birch tar is only produced at a narrow temperature interval $\left(350^{\circ} \mathrm{C}\right.$ and $\left.400^{\circ} \mathrm{C}\right)$. Heating times longer than $15 \mathrm{~min}$ have no effect on the quantity of tar produced. These findings, notwithstanding previous propositions of necessarily long heating times and larger tolerances for temperature, have important implications for our understanding of the investment in time needed for Palaeolithic birch tar making.
\end{abstract}

\section{Introduction}

Birch tar is the oldest manmade adhesive, dating back to the European Middle Palaeolithic (Mazza et al. 2006). It has recently attracted the attention of archaeologists because of its potential to yield information about the cognitive capacities and skills of Neanderthals and the technical knowledge employed to make birch tar in the European Palaeolithic and Mesolithic (e.g. Kozowyk et al. 2017; Niekus et al. 2019; Schmidt et al. 2019). Production pathways that could potentially have been used by Neanderthals in the Middle Palaeolithic include above-ground heating with the condensation method (Schmidt et al. 2019), heat treatment in earth-pits and/or under embers (Kozowyk et al. 2017) and specially built earthen raised structures (Osipowicz 2005). All proposed methods, except the condensation method, rely on the creation

Tabea J. Koch

tabea.koch@student.uni-tuebingen.de

1 Department of Early Prehistory and Quaternary Ecology, Eberhard Karls University of Tübingen, Tübingen, Germany

2 Applied Mineralogy, Department of Geosciences, Eberhard Karls University of Tübingen, Tübingen, Germany of chambers in which airflow is restricted to prevent the birch bark from burning (Koller et al. 2001). In such chambers, tar is formed by the distillation of suberin and the triterpenes present in birch bark (mainly betulin, lupeol, erythrodiol and betulinic acid) that condense from the so formed gaseous phase somewhere in the chamber (Rageot et al. 2019). Several authors discuss the temperature boundaries between which birch tar is formed in oxygen-depleted atmospheres. Propositions range from large temperature intervals between $250^{\circ} \mathrm{C}$ to above 500 ${ }^{\circ} \mathrm{C}$ (Kozowyk et al. 2017) to narrower intervals of $250-400{ }^{\circ} \mathrm{C}$ (Schenck and Groom 2018) or $400-500{ }^{\circ} \mathrm{C}$ (Kurzweil and Weiner 2013). The absence of a consensus on potential tar formation temperatures makes it difficult to draw conclusions on the conditions employed to make the known Neanderthal birch tar artefacts (if they were produced in oxygen-depleted environments). In addition, little is known about the relationship between heating duration and tar formation (for an exception, suggesting short heating times, see: Rageot et al. 2019). Without this information, it is difficult to understand the investment in time needed for birch tar making in restricted-oxygen conditions. To address these questions, we conduct a laboratory heating experiment using well-calibrated temperature and duration conditions. We heat-treat birch bark in sealed glass tubes, measuring whether, and how much, tar was formed depending on different heating conditions. 


\section{Materials and methods}

\section{Materials and sample preparation}

Bark was collected from dead birch trees (Betula pendula) lying on the ground of a birch forest (also, see the online supplementary material). Only well-preserved bark from the trunk portions of the trees was taken. Test tubes used for the experiment were made of soda-lime glass with a softening point at $\sim 700{ }^{\circ} \mathrm{C}$ (length: $130 \mathrm{~mm}$; outer diameter: $16 \mathrm{~mm}$; wall thickness; $0.8 \mathrm{~mm}$; straight rim). We used steel sieves (diameter: $20 \mathrm{~mm}$ ) that were bendable to fit into and stick to the walls of the test tubes. From these materials, we prepared 29 sealed test tubes as follows: first, glass tubes and birch bark (cut into strips) were weighed separately on a laboratory scale (precision: $0.00001 \mathrm{~g}$ ). Then, sieves were inserted into the test tubes to create a barrier for ash not to fall into the birch tar accumulating at the bottom of the tubes. Birch bark strips were rolled and placed above the sieves. Each piece of bark weighed approximately $1 \mathrm{~g}$ (for exact weight, see Table S1 in the online supplementary material). These filled tubes were again weighed. The tubes were then sealed by softening their rim over a Bunsen burner and closing them with laboratory tweezers. After sealing the tubes, they were weighed again to ensure that no glass was lost during closing. A rack was built from copper wires to hold five test tubes at a time in a tilted position in the electric furnace that was used for heating.

\section{Experimental setup}

We heat-treated the sealed test tubes at five different temperatures: $300,350,400,450$ and $500{ }^{\circ} \mathrm{C}$ (a heating ramp of $20 \mathrm{~min}$ was programmed for each temperature to prevent thermal shock of the glass). Six sealed test tubes were heated at each of the temperature steps for different durations: $15,30,45,60,90$ and 120 min (except for the $500{ }^{\circ} \mathrm{C}$ heating step, at which the 120 min duration was not conducted). The tubes were placed on the copper rack in an electric furnace. The furnace was turned on and the duration time was recorded from the moment the target temperatures were reached. After each target duration $(15,30,45,60,90,120 \mathrm{~min})$, one test tube was removed from the furnace. All test tubes were weighed after cooling to room temperature to measure the mass lost during heating. The sealed tubes were then scratched with a glasscutter, weighed again to measure the mass lost during scratching and then snapped open at the scratch. The remaining bark (or ash formed from it) and the sieves were removed so that only the residues formed in the tubes were left. Finally, all glass fragments, together with the residues (tar but also ash adhering to the tube walls that could not be scraped off), were weighed. The mass of the empty test tubes before the experiment and the mass lost during scratching were subtracted from this final measurement to approximate the mass of the residue formed in the tubes during the experiment.

\section{Results}

Although none of the test tubes shattered or broke, all samples lost mass after heating to the different temperatures. This means that all samples released pressure that built up internally during heating (fissures were visible after heating on many sealed tubes), allowing air exchange with the atmosphere in the oven. The magnitude of mass loss increased with rising temperatures (Fig. 1a) $\left(300^{\circ} \mathrm{C}: 0.1-0.14 \mathrm{~g} ; 350{ }^{\circ} \mathrm{C}: 0.19-0.29\right.$ g; $400{ }^{\circ} \mathrm{C}: 0.71-0.82 \mathrm{~g} ; 450{ }^{\circ} \mathrm{C}: 0.83-0.89 \mathrm{~g} ; 500{ }^{\circ} \mathrm{C}: 0.85$ $0.94 \mathrm{~g}$ ). The mass of residue that formed in the test tubes, as per temperature and duration, is shown in Fig. 1b. Sealed test tubes before and after heating are shown in Fig. 1c. No tar was produced at any of the duration steps of the $300{ }^{\circ} \mathrm{C}$ heating experiment and bark rolls were only slightly charred (Fig. 1f). Droplets of a light brown to yellow liquid formed at the bottom of the tubes (Fig. S2a of the supplementary material). In the $350{ }^{\circ} \mathrm{C}$ heating experiment, all test tubes contained recognisable tar. In the $350{ }^{\circ} \mathrm{C}$ tubes heated for 15 and 30 min, tar stuck to the walls of the tubes or was still clogged in the bark roll (Fig. 1d). After 45, 60 and 90 min, tar flowed to the bottom of the tubes (Fig. S2b and S3 of the supplementary material). The highest tar yield $(0.27075 \mathrm{~g})$ was produced after heating to $350{ }^{\circ} \mathrm{C}$ for $90 \mathrm{~min}$ (Fig. 1e). After $120 \mathrm{~min}$ of heating at $350{ }^{\circ} \mathrm{C}$, a comparatively low amount of tar was produced that mostly stuck to the walls of the tube (Fig. S3 of the supplementary material). When removing the charred bark of the $350{ }^{\circ} \mathrm{C}$ experiments, we scraped the ashes from the tube walls, leaving behind only tar adhering to the glass walls. Tar remaining in the charred bark rolls was removed along with it. All heating durations of the $400{ }^{\circ} \mathrm{C}$ experiment produced tar, part of which was observed at the bottom of the tubes and part of which stuck to the tube walls. After heating to 450 and $500{ }^{\circ} \mathrm{C}$, all tubes were partially black (Fig. S3 of the supplementary material). However, no tar was observed in any of these tubes. Only small masses of a black residue, composed of ash and a soot-like layer, were observed. Ash from charred bark held above the sieves was powdery and could be removed as fine lightweight residue (Fig. S2c and $\mathrm{d}$ of the supplementary material). Thus, usable birch tar with adhesive properties was only produced at 350 and $400{ }^{\circ} \mathrm{C}$ (Table 1).

\section{Discussion and conclusion}

\section{The quality and meaning of our data}

Some sealed tubes burst while the furnace heated up. In this case, the experiment was repeated so that only seemingly intact tubes were analysed (thus, our six duration steps were conducted during several runs at the same temperature). However, all of the sealed test tubes allowed for (most likely 

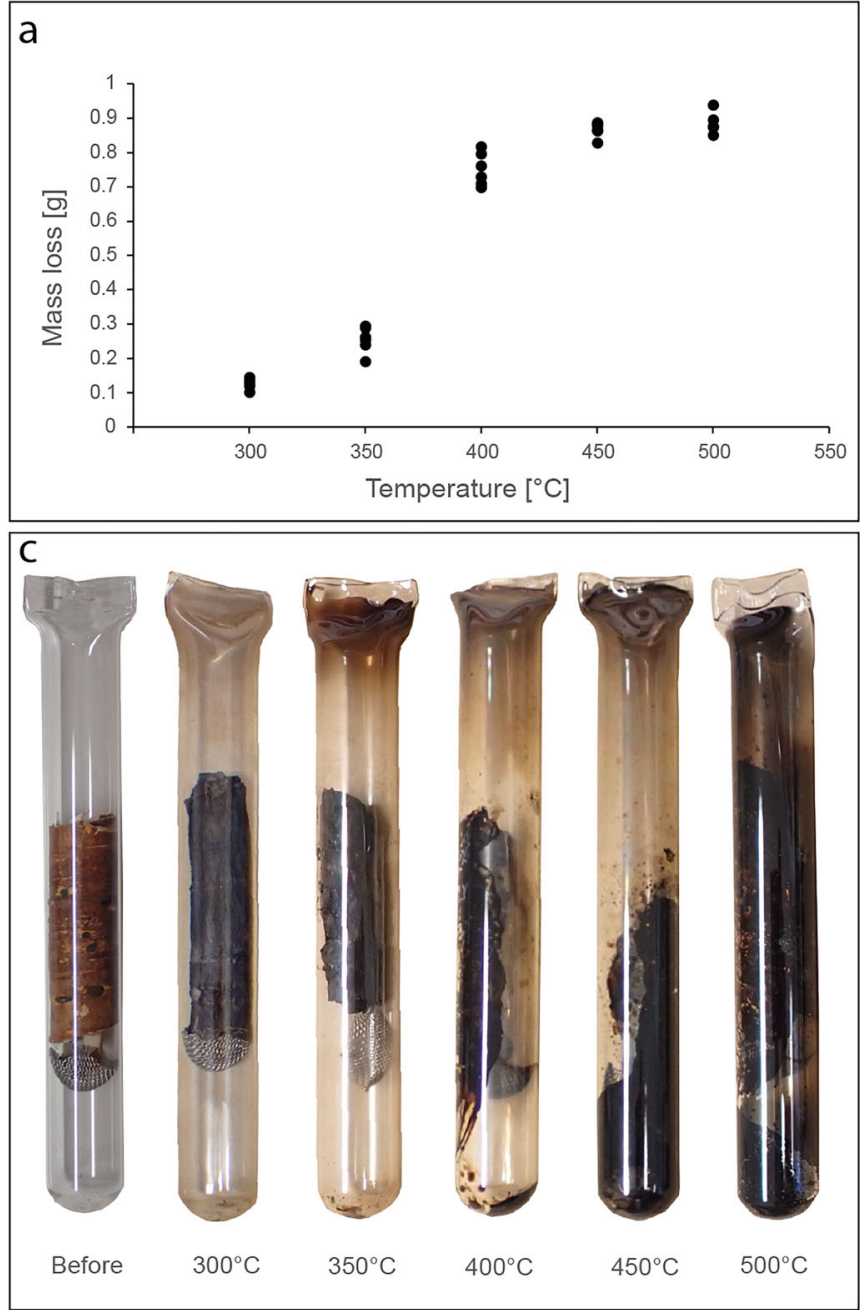

Fig. 1 a Mass loss in sealed test tubes for each heating temperature. Individual dots are tubes heated for different durations. b The mass of residue formed at different temperatures, as per $1 \mathrm{~g}$ of bark. Individual dots are annotated with their respective heating duration in min for both temperatures at which usable birch tar was produced: 350 and $400{ }^{\circ} \mathrm{C}$. c

restricted) air exchange with the oven atmosphere. None of the tubes remained airtight. Our experiments therefore provide good approximations of the atmospheric conditions predominating in actualistic birch tar making experiments where chambers undergrounded or within embers are unlikely to be completely sealed. There are a few potential sources of
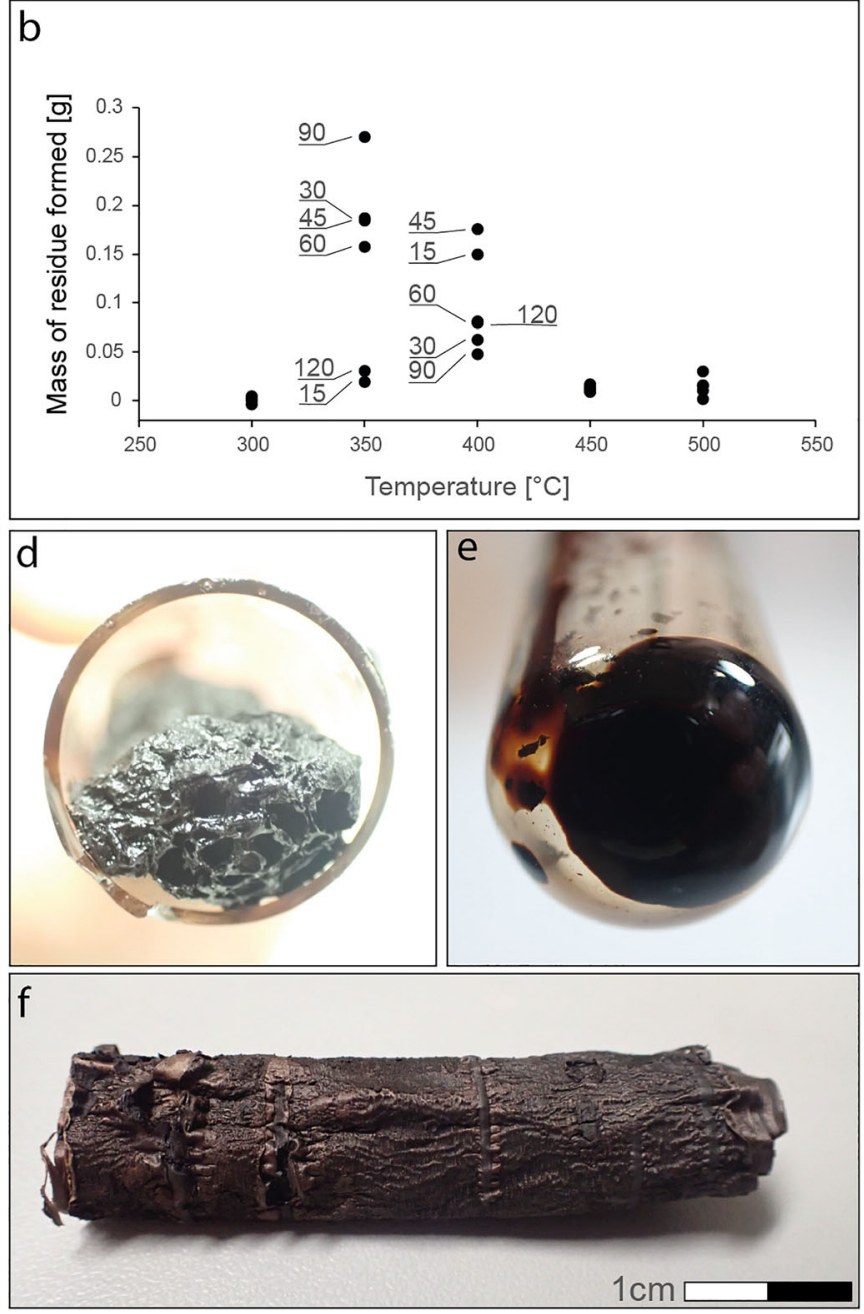

Sealed test tubes before and after heating to different temperatures for 15 min. d Charred bark roll inside a test tube heated to $350^{\circ} \mathrm{C}$ for $15 \mathrm{~min}$. e Tar yield at the bottom of a test tube heated to $350{ }^{\circ} \mathrm{C}$ for $90 \mathrm{~min}$. f Slightly charred bark roll after heating to $300{ }^{\circ} \mathrm{C}$ for $15 \mathrm{~min}$ from which no tar was produced

uncertainty for our data. For example, the actual tar yield for the $350{ }^{\circ} \mathrm{C}$ experiments might be slightly higher than reported because some of the tar that was stuck in the charred bark rolls was removed with the ashes/bark remains. Tar yields at $350^{\circ}$ should therefore be regarded as minimum values. Based on our data from the higher temperature experiments at 450 and
Table 1 Masses of residue (in $\mathrm{g}$ ) per $1 \mathrm{~g}$ of birch bark formed at different temperature and heating durations. Usable tar (recognisable as such) was only produced at 350 and $400^{\circ} \mathrm{C}$. Note that the negative value at $300{ }^{\circ} \mathrm{C}$ and $30 \mathrm{~min}$ may be the result of losing a small glass fragment during opening of the tube

\begin{tabular}{ccrcccc}
\hline Temperature $\left[{ }^{\circ} \mathrm{C}\right]$ & $15 \mathrm{~min}$ & \multicolumn{1}{l}{$30 \mathrm{~min}$} & $45 \mathrm{~min}$ & $60 \mathrm{~min}$ & $90 \mathrm{~min}$ & $120 \mathrm{~min}$ \\
\hline 300 & 0.00186 & -0.00339 & 0.00509 & 0.00254 & 0.00202 & 0.00116 \\
350 & 0.01983 & 0.18732 & 0.18464 & 0.15774 & 0.27075 & 0.03085 \\
400 & 0.14996 & 0.06272 & 0.17601 & 0.08121 & 0.04819 & 0.07972 \\
450 & 0.01068 & 0.01417 & 0.01316 & 0.01317 & 0.01727 & 0.00929 \\
500 & 0.01613 & 0.01590 & 0.03023 & 0.00188 & 0.01084 & - \\
\hline
\end{tabular}


$500{ }^{\circ} \mathrm{C}$, it cannot be decided whether tar was formed during the heating ramp, volatilising once the target temperatures were reached, or whether it formed during the first minutes at target temperature but volatilised before the first tube was removed at the 15 min mark. What is certain is that if tar formed during heating, it did not survive even short-term heating above $400{ }^{\circ} \mathrm{C}$. The precision of our temperatures must be regarded with an error of $\sim \pm 10^{\circ} \mathrm{C}$. Temperature fluctuations were caused by the furnace over- and undershooting the target temperatures while stabilising after the door was opened.

The meaning of our data for Neanderthal birch tar making can only be understood by asking what our experiment is representative of in terms of real-world techniques. Some authors (e.g. Kurzweil and Todtenhaupt 1992; Rageot et al. 2019) separate potential Neolithic techniques into singleand double-pot techniques, depending on whether tar is collected in the same chamber where the bark is held or in a separate chamber. Aceramic birch tar making techniques can roughly be separated into similar categories. Kozowyk et al. (2017) report two techniques that approximate single-pot procedures: heating in an earthen pit covered by embers and heating in a pile of embers. In both techniques, a chamber is created by either sediment or the exterior of a bark roll. While there may be significant temperature differences at different locations in sediment pits, temperatures within a pile of embers were found to be homogeneous (Kozowyk et al. 2017). Our heating experiment most likely approximates the conditions reigning in Neolithic single-pots and aceramic tar making in piles of embers as reported by Kozowyk et al. (2017). It most likely does not simulate the conditions prevailing in single- or double-chambered structures made from clay or sediment that have greater temperature gradients. In these techniques, the range of temperatures at which birch tar forms could include maximum temperatures above $400{ }^{\circ} \mathrm{C}$ because tar is collected in cooler parts of the structure where it is prevented from volatilising. However, the lower end of our temperature range $\left(350^{\circ} \mathrm{C}\right)$ is certainly valid for all birch tar making techniques.

\section{Comparison with previously published data}

Rageot et al. (2019) conducted similar heating experiments with sealed glass tubes and found that in their tubes heated to $300{ }^{\circ} \mathrm{C}$, only yellow liquid was formed. Like ourselves, they observed tar formation at $350{ }^{\circ} \mathrm{C}$. However, our finding that birch tar only forms at 350 and $400{ }^{\circ} \mathrm{C}$ is in contradiction with other previous findings based on actualistic heating experiments. Kozowyk et al. (2017) for example state that '... [tar production from] birch bark [...] can be as low as $250-300{ }^{\circ} \mathrm{C}^{33}$ and over $500{ }^{\circ} \mathrm{C}^{34-36}$, (Op. cit. p.4). The discrepancy with our data might be explained by the fact that the references they cite for this statement (33- 36 in Kozowyk et al. 2017) all describe the extraction of chemical components from birch bark or wood under vacuum in a pyrolysis chamber attached to a gas-chromatography unit (Fagernäs et al. 2012; Nilsson et al. 1999; Pakdel et al. 2002; Puchinger et al. 2007; i.e. references 33- 36 in Kozowyk et al. 2017). These conditions, suitable for the extraction of tar-forming chemicals in gaseous form for gas-chromatographic analysis, can be expected to be different from the temperature ranges at which usable tar is formed. In their own experiments, Kozowyk et al. (2017) find that temperatures in the middle of bark rolls heated in piles of embers remained below $260^{\circ} \mathrm{C}$ and still produced tar. Our experimental data are in contradiction with these measurements, suggesting that birch tar does not form below $350{ }^{\circ} \mathrm{C}$. This discrepancy might be explained by the difficulty to measure accurate reaction temperatures in actualistic experiments where most factors cannot be controlled. Other authors report minimum values for tar formation such as $220-280{ }^{\circ} \mathrm{C}$ (Osipowicz 2005) or temperature ranges not based on direct experimental data such as $400-500{ }^{\circ} \mathrm{C}$ (Kurzweil and Weiner 2013). These values cannot be comparted meaningfully with our experimental data. There are, however, some reports of heating temperatures identified as allowing tar formation in actualistic experiments that agree with our findings. Some (Groom et al. 2015) report 350$400{ }^{\circ} \mathrm{C}$ to be the ideal temperature range, others (Schenck and Groom 2018) experiment with temperatures above $320^{\circ} \mathrm{C}$.

\section{Significance}

Our experiments show that birch tar produced with a 'singlepot'-like method forms at temperatures between $350 \pm 10$ and $400 \pm 10^{\circ} \mathrm{C}$. There is no clear trend of tar yield as a function of heating time. In other words, short heating times already produce birch tar. This means that, theoretically, the minimum time investment to produce usable amounts of birch tar is as little as $15 \mathrm{~min}$ (in terms of reaction kinetics). However, this does not factor in heating ramp and cooling or the building of a heating structure, which are expected to increase time investment significantly. What is certain is that a minimum temperature between 310 (the upper range of our $300 \pm 10{ }^{\circ} \mathrm{C}$ heating step) and $350 \pm 10^{\circ} \mathrm{C}$ must be reached to produce tar. The upper limit of tar formation lies below $450 \pm 10{ }^{\circ} \mathrm{C}$, although this might not apply to 'double-pot'-like tarmaking methods (including the earthen raised structure) because of the temperature gradient in them. Only further laboratory experiments may shed light on the upper temperatures allowed for the more complex 'double-pot'-like techniques.

Supplementary Information The online version contains supplementary material available at https://doi.org/10.1007/s12520-021-01352-x.

Acknowledgements We are indebted to A. Flicker for her assistance with the heating experiment. We also thank A. Gutekunst for his assistance in collecting birch bark. 
Funding Open Access funding enabled and organized by Projekt DEAL. P. Schmidt received funding from the Deutsche Forschungsgemeinschaft (DFG) (grant number SCHM 3275/3-1).

Open Access This article is licensed under a Creative Commons Attribution 4.0 International License, which permits use, sharing, adaptation, distribution and reproduction in any medium or format, as long as you give appropriate credit to the original author(s) and the source, provide a link to the Creative Commons licence, and indicate if changes were made. The images or other third party material in this article are included in the article's Creative Commons licence, unless indicated otherwise in a credit line to the material. If material is not included in the article's Creative Commons licence and your intended use is not permitted by statutory regulation or exceeds the permitted use, you will need to obtain permission directly from the copyright holder. To view a copy of this licence, visit http://creativecommons.org/licenses/by/4.0/.

\section{References}

Fagernäs L, Kuoppala E, Tiilikkala K, Oasmaa A (2012) Chemical composition of birch wood slow pyrolysis products. Energy Fuel 26: 1275-1283. https://doi.org/10.1021/ef2018836

Groom P, Schenck T, Pedersen GM (2015) Experimental explorations into the aceramic dry distillation of Betula pubescens (downy birch) bark tar. Archaeol Anthropol Sci 7:47-58. https://doi.org/10.1007/ s12520-013-0144-5

Koller J, Baumer U, Mania D (2001) High-tech in the middle Palaeolithic: Neandertal-manufactured pitch identified. Eur J Archaeol 4:385-397. https://doi.org/10.1179/eja.2001.4.3.385

Kozowyk PRB, Soressi M, Pomstra D, Langejans GHJ (2017) Experimental methods for the Palaeolithic dry distillation of birch bark: implications for the origin and development of Neandertal adhesive technology. Sci Rep 7:8033. https://doi.org/10.1038/ s41598-017-08106-7

Kurzweil A, Todtenhaupt D (1992) Technologie der Holzteergewinnung. Acta Praehist Archaeol 23:63-91

Kurzweil A, Weiner J (2013) Wo sind die Retorten? - Gedanken zur allothermen Herstellung von Birkenpech Experimentelle Archaologie in Europa 12:10-19
Mazza PPA, Martini F, Sala B, Magi M, Colombini MP, Giachi G, Landucci F, Lemorini C, Modugno F, Ribechini E (2006) A new Palaeolithic discovery: tar-hafted stone tools in a European MidPleistocene bone-bearing bed. J Archaeol Sci 33:1310-1318. https://doi.org/10.1016/j.jas.2006.01.006

Niekus MJLT, Kozowyk PRB, Langejans GHJ, Ngan-Tillard D, van Keulen H, van der Plicht J, Cohen KM, van Wingerden W, van Os B, Smit BI, Amkreutz LWSW, Johansen L, Verbaas A, Dusseldorp GL (2019) Middle Paleolithic complex technology and a Neandertal tar-backed tool from the Dutch North Sea Proceedings of the National Academy of Sciences:201907828 doi:https://doi. org/10.1073/pnas.1907828116

Nilsson M, Ingemarsson A, Pedersen JR, Olsson JO (1999) Slow pyrolysis of birch (Betula) studied with GC/MS and GC/FTIR/FID. Chemosphere 38:1469-1479. https://doi.org/10.1016/S00456535(98)00347-6

Osipowicz G (2005) A method of wood tar production, without the use of ceramics. Reconstr Exp Archaeology EuroREA 2:11-17

Pakdel H, Népo Murwanashyaka J, Roy C (2002) Extraction of betulin by vacuum pyrolysis of birch bark. Journal of Wood Chemistry and Technology 22:147-155. https://doi.org/10.1081/WCT-120013359

Puchinger L, Sauter F, Leder S, Varmuza K (2007) Studies in organic archaeometry VII- differentiation of wood and bark pitches by pyrolysis capillary gas chromatography. (PY-CGC) Annali di chimica 97:513-525. https://doi.org/10.1002/adic.200790034

Rageot M, Théry-Parisot I, Beyries S, Lepère C, Carré A, Mazuy A, Filippi JJ, Fernandez X, Binder D, Regert M (2019) Birch bark tar production: experimental and biomolecular approaches to the study of a common and widely used prehistoric adhesive. J Archaeol Method Theory 26:276-312. https://doi.org/10.1007/s10816-0189372-4

Schenck T, Groom P (2018) The aceramic production of Betula pubescens (downy birch) bark tar using simple raised structures. A viable Neanderthal technique? Archaeol Anthropol Sci 10:19-29. https://doi.org/10.1007/s12520-016-0327-y

Schmidt P, Blessing M, Rageot M, Iovita R, Pfleging J, Nickel KG, Righetti L, Tennie C (2019) Birch tar production does not prove Neanderthal behavioral complexity. Proc Natl Acad Sci 116: 17707. https://doi.org/10.1073/pnas.1911137116

Publisher's note Springer Nature remains neutral with regard to jurisdictional claims in published maps and institutional affiliations. 